\title{
Photoprotection among young children: assessment of mothers' awareness and health behaviours
}

\author{
Magdalena Kruzel ${ }^{1}$, Aleksandra Tobiasz ${ }^{1}$, Magdalena Łyko ${ }^{1}$ Jacek C. Szepietowski², Alina Jankowska-Konsur ${ }^{2}$ \\ ${ }^{1}$ Student Research Group of Experimental Dermatology, Department of Dermatology, Venereology and Allergology, \\ Wroclaw Medical University, Wroclaw, Poland \\ ${ }^{2}$ Department of Dermatology, Venereology and Allergology, Wroclaw Medical University, Wroclaw Poland \\ Adv Dermatol Allergol 2022; XXXIX (2): 392-396 \\ DOI: https://doi.org/10.5114/ada.2021.105820
}

\begin{abstract}
Introduction: Due to the increasing incidence of skin cancer in the last decades a wide promotion of proper sun protection is needed. Mothers and their children commonly spending time outdoors are particularly vulnerable to the harmful effects of sunlight.

Aim: To assess health awareness and behaviours connected to sun protection in the group of mothers of children under 6 years of age.

Material and methods: An online survey containing 23 questions (19 closed and 4 open) was carried out between July and August 2019. One hundred and seven women (mean age: $30.7 \pm 4$.3years) participated in the study. The mean age of children was $1.9 \pm 1.6 y e a r s$ (range: $0-6$ years).

Results: One hundred and five (98.1\%) mothers declared using sunscreen. Of them, 36 women used sunscreen only in summer, while 14 women applied sunscreen all year. Mothers of younger children used sunscreen all year round significantly more often $(p=0.041)$ compared to mothers of older children. Mothers of children under the age of 1 used sunscreen when staying in the shade more often $(p=0.025)$ than mothers of older children. Only $14(13.3 \%)$ women declared applying sunscreen on their children during cloudy weather.

Conclusions: A good photoprotection awareness of mothers, especially with respect to the youngest children was observed. However, a need for further education regarding certain photoprotection aspects (proper application and damaging effect of UVA) is necessary.
\end{abstract}

Key words: sun protection, preschool children, mothers, education.

\section{Introduction}

Incidence of skin cancers worldwide has been constantly increasing for the past two decades [1]. This rise might be attributed to higher sun exposure resulting from a changing lifestyle, which promotes physical activity in the fresh air.

Photoprotection is one of the most important elements of preventing the skin from the harmful effects of sun exposure and development of skin cancers. According to the world literature, sunburn during the first years of life is a major risk factor in the paediatric population and increases the risk of squamous cell carcinoma (SCC) in later life [2].

Skin of infants and young children, mainly under the age of 3 , contains less melanin and has thinner stratum corneum [3, 4]. The basal layer has a large number of stem cells that can easily mutate when they are exposed to ultraviolet radiation (UVR) [5]. As a consequence, it leads to a deeper penetration of UVR into the skin and causes its damage [3]. Therefore, an introduction of sun protective measures in the very first days and years of life is essential [6]. In the group of young children an indispensable part of photoprotection is the use of sunscreens as well as additional protective methods, such as avoiding excessive exposure to UV radiation, wearing protective clothing, sunglasses and caps [5]. In the group of infants, pre-school and school children, used photoprotection usually depends on their parents, which is why parents' awareness and protective behaviour against the harmful effects of sunlight is of major importance [7].

\section{Aim}

The aim of the study was to assess health awareness and behaviours connected to the sun protection in mothers of children under the age of 6.

Address for correspondence: Prof. Jacek Szepietowski MD, PhD, Department of Dermatology, Venerology and Allergology, Wroclaw Medical University, 1 Chalubinskiego St, 50-368 Wroclaw, Poland, phone: +48 78422 86, e-mail: jacek.szepietowski@umed.wroc.pl Received: 3.03.201, accepted: 16.03.2021. 


\section{Material and methods}

For the needs of the study, we proposed a set of questions using Google Documents. The survey was designed based on an interview with 10 mothers regarding their beliefs, behaviours, habits and needs related to photoprotection. It consisted of 23 questions (15 single-choice, 4 multiple-choice and 4 open questions). The survey was posted online on the 18 maternity groups on Facebook between July and August 2019. Incomplete sheets were rejected by the system. All received questionnaires were analysed.

\section{Statistical analysis}

The IBM SPSS Statistics 25 program was used for the analysis. The correlation matrix analysis, tests for the difference between two structure indices and $\chi^{2}$ test was performed for the data. P-value used in testing of the null hypothesis was 0.05 .

\section{Results}

\section{Respondents}

One hundred and seven women aged 18-44 years took part in the survey (average age: $30.7 \pm 4.3$ years). The age of children varied between 1 month and 6 years (average age: $1.9 \pm 1.6$ years). Among the surveyed women, 80 (74.8\%) had university education, 26 (24.3\%) secondary education and 1 (0.9\%) person declared primary education. Two (1.9\%) respondents declared a history of skin cancer (melanoma) in the family.

\section{Outdoor activity}

Seventy-seven (72.0\%) respondents stated that they spend time outdoors with their child each day of the week, 8 (7.5\%) women six times a week, 9 (8.5\%) five times a week, 7 (6.5\%) four times a week, 4 (3.7\%) three times a week, $1(0.9 \%)$ person two times a week and $1(0.9 \%)$ person once a week. The walks usually lasted from 1 to $1.5 \mathrm{~h}$ (36 respondents, 33.6\%) or from $1.5 \mathrm{~h}$ to $2 \mathrm{~h}$ (33 persons, 30.8\%).

\section{The sunscreen use}

One hundred and five (98.1\%) mothers declared applying sunscreen on their children. The following data applies only to this group of women.

\section{The sunscreen choice}

Among the mothers using sunscreens, when choosing a sunscreen, women paid attention to different qualities of products. Ninety-two (87.6\%) mothers indicated taking the value of sun protection factor (SPF) into consideration. Fifty-four (51.4\%) preferred to choose the product on the basis of its composition, 34 (32.4\%) pointed out that formulation is important and 3 (2.9\%) women chose their products because of the packaging. Forty-seven (44.8\%) respondents indicated that they choose sunscreen with mineral filter for their children, 2 (1.9\%) mothers use chemical filters and 16 (15.2\%) mixed filters. Nonetheless, 40 (38.1\%) respondents did not know which type of filter they apply on their children. Fourteen (13.3\%) women stated that from time to time they use a sunscreen for adults for their children. Most mothers declared using sunscreens with SPF $50+$ (57 persons; 54.3\%) and SPF 30 (35 persons; 33.3\%). Sixty-eight (64.8\%) mothers declared that they usually buy products at pharmacies, 49 (46.7\%) women stated that they generally purchase products at beauty stores and 20 (19.1\%) women online. Moreover, 79 (75.2\%) women indicated that they buy sunscreens at one place only (pharmacy, beauty store or online), 20 of them (19.1\%) marked two different places and 6 (5.7\%) women declared buying sunscreens at all mentioned locations. Forty-three (40.9\%) mothers usually used a single packaging of the sunscreen in less than 6 months. Twenty-six (24.8\%) women used it in 6-12 months and 4 (3.8\%) in more than 12 months. Furthermore, 23 (21.9\%) women used sunscreen until the expiry date and 9 (8.6\%) mothers did not know for how long they use a packaging of sunscreen.

\section{The sunscreen application}

Among the women using sunscreens, 39 (37.2\%) applied it on their child's skin once a day, just before a walk. Thirty-one $(29.5 \%)$ respondents stated that they apply a sunscreen on their children once, approximately 15 min before the walk, while 35 (33.3\%) respondents applied a product several times, depending on the duration of the walk. Fifteen (14.3\%) children experienced a sunburn or erythema at least once after a walk despite the use of sunscreen. While after using the sunscreen $4(3.8 \%)$ children suffered sunburns or erythema. Among the women using sunscreens, 64 (61.0\%) mothers applied sunscreen on children who were not directly exposed to the sun. Fifty-three (50.5\%) respondents declared that they use sunscreen even when the stroller is covered by an umbrella or a diaper.

On the other hand, only 14 (13.3\%) women declared that they apply sunscreen on their children during cloudy weather. Fifty-one (48.6\%) women stated that they use the sunscreen always when a child is in the shade, 16 (15.2\%) women sometimes and 38 (36.2\%) never. Among the mothers of children under 1 year of age, $22.2 \%$ of respondents ( 8 out of 36 ) did not use sunscreen when staying in the shade, whereas in the group of children aged 1 to 2 years $25.0 \%$ (7 out of 28 ) of mothers did not apply the sunscreen and neither did $48.8 \%$ (20 out of 41) of respondents in the age group of mothers of children over 2 years of age.

There was a statistically significant difference between the age of a child and the use of sunscreen when 

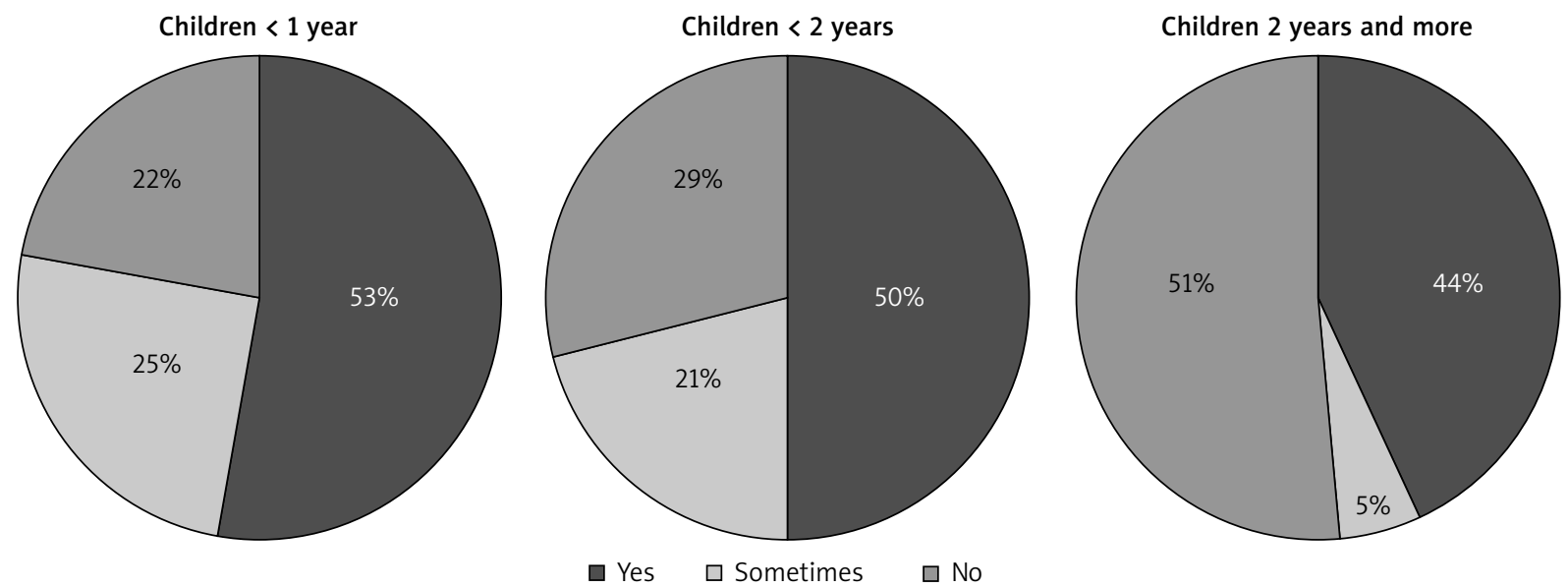

Figure 1. The use of sunscreen in the group of children when staying in the shade depending on their age

staying in the shade. Mothers of children under the age of 1 used sunscreen while staying in the shade more often $(p=0.025)$ than the mothers of children of 2 years of age or more (Figure 1).

Among all the respondents, 14 (13.3\%) mothers declared that they apply sunscreen on their children all year round. Thirty-six (34.3\%) use these products only in summer. Eleven (10.5\%) mothers admitted that they apply sunscreen on their offspring for most of the year, except winter.

There was a statistically significant difference ( $p=0.041$ ) between the age of a child and the year-round sunscreen use. The younger the child was, the more willingly sunscreen was applied through the year (Figure 2).

Among the mothers using sunscreen, 85 (81.0\%) declared that they apply this product on themselves. Mothers seemed to apply sunscreen more often on their children than on themselves, however, no statistical significance was found ( $p>0.05)$. Ninety-nine $(94.3 \%)$ women stated that they believe in safety of sunscreens. Ac- cording to $6(5.7 \%)$ respondents, the safety of the cream depends on its composition.

\section{Discussion}

Health behaviours of parents are of great importance for the future lifestyle of children, especially the younger ones. Photoprotection is the most effective known method, which prevents the skin against the development of skin cancers and melanoma [1-8].

In the study we focused on behaviours of mothers because they tend to spend more time with children in the first years of their lives. According to the findings of Bodekaer Larsen et al. [9], mothers' actions regarding sun protection and exposure to the sun had a significant impact on such behaviours of their children.

In our study, the vast majority of respondents (98.1\%) declared the use of the sunscreen. Surveyed mothers tended to apply sunscreens with a higher value of SPF on their children (SPF 50+ -57 mothers (54.3\%) and sun-
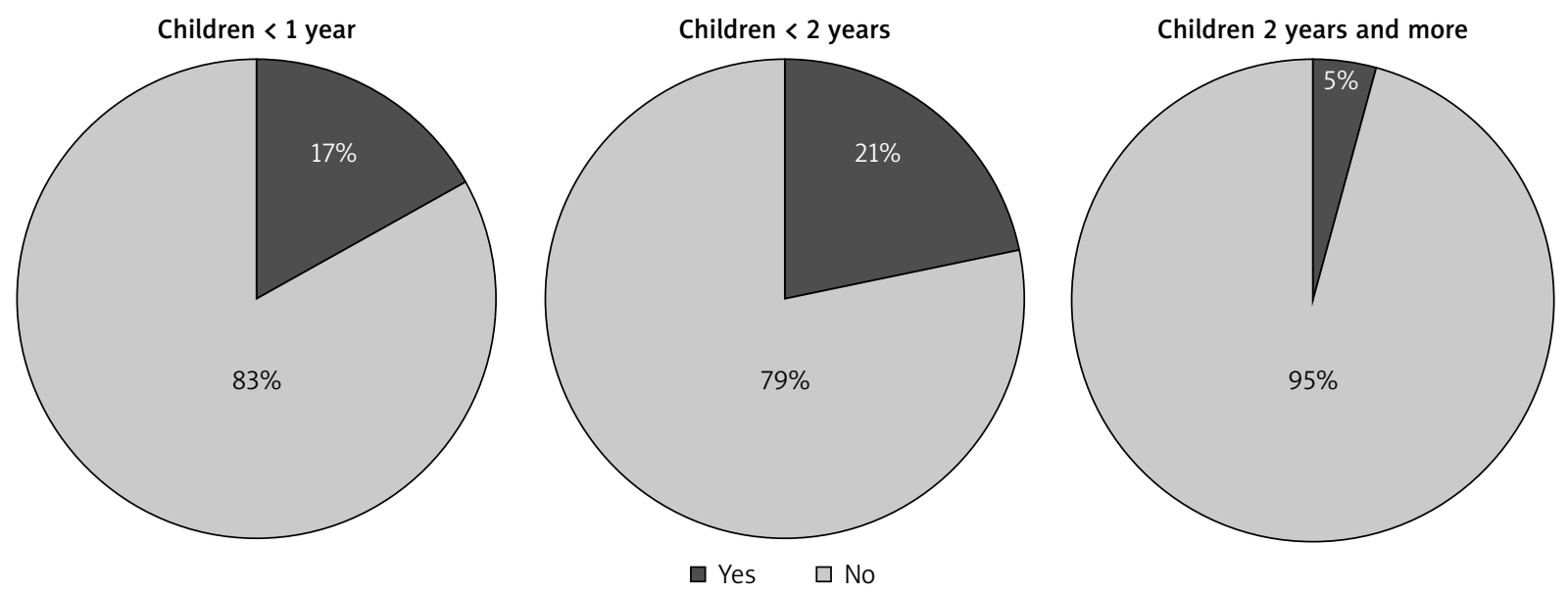

Figure 2. The all year long application of sunscreens in the group of children depending on their age 
screens with SPF $30-35$ (33.3\%)). On the other hand, the majority of mothers did not wait at least 30 min after application for better absorption of the cream. Similarly, in the American study, the majority of mothers tended to choose sunscreens with higher values of SPF (15 and more) for their children but did not follow the rule of earlier cream application [10].

According to our data, mothers seemed to apply sunscreen more often on their children than on themselves. However, there was no statistically significant difference between the use of photoprotection for a child and for oneself. Similarly, Mortier et al. [11] found that parents tend to protect their children against the sun better than they protect themselves. A smaller percentage of women (3.8\%) reported a sunburn episode of their children after the use of the sunscreen, than without such use (14.3\%), nevertheless such situations appeared. Sunburn after using the sunscreen might be connected to many factors, such as a thin layer of the cream applied, formulations which are too liquid, false sense of security after application and overestimating of the role of the shade, hats and other sun protection methods [12].

According to our study, a relatively small percentage of women stated applying sunscreen on their children during cloudy weather (13.3\%). This can indicate that mothers are not aware of the possibility of sunburn during cloudy weather in summer. Gefeller et al. [13] mentioned a similar problem - parents overestimated a protective role of clouds during summer and underestimated the possibility of being sunburnt during cloudy weather. Without a doubt, a need for education about the damaging effects of UVA radiation on the skin is necessary.

Approximately $38.1 \%$ of women were not aware of a type of filter applied on their children and did not take it under consideration when choosing the proper sunscreen. The value of SPF was the most important factor (87.6\%). For children under 2 years of age and the ones with sensitive, allergy-prone skin mineral filters are recommended [6].

We found a statistically significant difference between the age of a child and the use of sunscreen all year long. The younger the child is, the more often sunscreens are used all year long. Our findings are consistent with the data of Thoonen et al. [14] who demonstrated that parents tend to apply sunscreen more frequently on the youngest children. This might result from greater care and caution of parents towards the youngest ones.

We are aware that our online research carries a risk of bias because it excludes women not using the internet, not involved in maternity forums and not interested in the subject of photoprotection. This group includes active, well-educated mothers, freely using online tools and freely finding the content they need. In this group, education on health promotion brings the expected beneficial effects. However, one should also consider a group of uninvolved mothers and reaching this group should be a priority for future health promotion.

In conclusion, good photoprotection awareness of mothers, especially towards the youngest children was observed. However, a need for further education regarding certain photoprotection aspects (proper application and damaging effect of UVA) is necessary. Further studies on a larger group is needed, including women from different backgrounds.

\section{Conclusions}

Photoprotection used from an early age prevents the harmful effects of ultraviolet radiation (UVR) on the skin. Caregivers are responsible for protecting children from the sun. The aim of the study was to examine how mothers protect their children against the harmful effects of UVR. In our study the majority of mothers used sunscreens with high SPF (SPF 50+). Respondents used sunscreen relatively rarely during cloudy weather. The mothers of the youngest children (under 1 year of age) statistically more often used sunscreen all year round and when staying in the shade comparing to the mothers of older children.

\section{Conflict of interest}

The authors declare no conflict of interest.

\section{References}

1. Leiter U, Eigentler T, Garbe C. Epidemiology of skin cancer. Adv Exp Med Biol 2014; 810: 120-40.

2. Armstrong BK. How sun exposure causes skin cancer: an epidemiological perspective. In: Prevention of Skin Cancer. Hill D, Elwood JM, English DR. Kluwer Academic Publishers, Springer, Dordrecht, The Netherlands 2004; 3: 89-116.

3. Cestari T, Buster K. Photoprotection in specific populations: children and people of color. I Am Acad Dermatol 2017; 76: 110-21.

4. Stamatas GN, Nikolovski J, Luedtke MA, et al. Infant skin microstructure assessed in vivo differs from adult skin in organization and at the cellular level. Pediatr Dermatol 2010; 27: 125-31.

5. Narbutt J, Wolska H, Kaszuba A, et al. Photoprotection. Recommendations of the Polish Dermatological Society. Part 2: Sunscreen use. Dermatol Rev 2018; 105: 30-40.

6. Quatrano NA, Dinulos JG. Current principles of sunscreen use in children. Curr Opin Pediatr 2013; 25: 122-9.

7. Berneburg M, Surber C. Children and sun protection. Br J Dermatol 2009; 161: 33-9.

8. http://onkologia.org.pl/nowotwory-skory-c44/

9. Bodekćr Larsen M, Petersen B, Philipsen PA, et al. Sun exposure and protection behavior of danish farm children: parental influence on their children. Photochem Photobiol 2014; 90: 1193-8.

10. Buller DB, Cokkinides V, Hall HI, et al. Prevalence of sunburn, sun protection, and indoor tanning behaviors among Americans: review from national surveys and case studies of 3 states. J Am Acad Dermatol 2011; 65: 114-23. 
11. Mortier L, Lepesant P, Saiag P, et al. Comparison of sun protection modalities in parents and children. J Eur Acad Dermatol Venereol 2015; 29: 16-9.

12. Autier P, Boniol M, Dore JF. Sunscreen use and increased duration of intentional sun exposure: still a burning issue. Int J Cancer 2007; 121: 1-5.

13. Gefeller O, Uter W, Pfahlberg AB. Good, but not perfect: parental knowledge about risk factors for skin cancer and the necessity of sun protection in Southern Germany. Pediatr Dermatol 2015; 32: 159-60.

14. Thoonen K, Schneider F, Candel M, et al. Childhood sun safety at different ages: relations between parental sun protection behavior towards their child and children's own sun protection behavior. BMC Public Health 2019; 19: 1044. 